\title{
Targeting DAMP Activation of Toll-Like Receptors: Novel Pathways to Treat Rheumatoid Arthritis?
}

\author{
Theresa H. Page and Kim S. Midwood \\ Kennedy Institute of Rheumatology, Imperial College of Science, \\ Technology and Medicine, London \\ UK
}

\section{Introduction}

Inflammation is a necessary response to infection and injury by which the invading pathogen and/or damaged cells are cleared. Under normal circumstances this is a tightly controlled and transient process. However, in conditions such as rheumatoid arthritis (RA) these regulatory mechanisms appear inactive or ineffective such that inflammation progresses unchecked. This results in the pain, swelling and bone and cartilage destruction that define this disease.

The etiology of RA initiation is still uncertain, but increasing evidence points to a key role for the toll-like receptor (TLR) family in driving aberrant inflammation in the joint. TLRs were originally identified as receptors for exogenous pathogen associated molecular patterns (PAMPs) of bacterial, fungal or viral origin, which initiate inflammation in response to microbial infection. Perhaps of more interest in the context of RA however, is the role that these molecules play in the recognition of endogenous danger signals or DAMPs (damage associated molecular patterns).

DAMPs are generated by both infection-induced and sterile tissue damage. They include a wide range of molecules including intracellular proteins such as high mobility group protein 1 (HMGB1), cell derived nucleic acids and extracellular matrix molecules such as tenascin-C and fibrinogen. High levels of DAMPs are present in both the RA synovium and in the peripheral circulation in RA patients. Accumulating evidence from both human studies and experimental animal models now suggests that these molecules may be critical to the persistence of the inflammatory state in RA. Moreover, targeting TLRs and their downstream signalling pathways is emerging as a potentially tractable means for treating a range of inflammatory conditions, including RA and its associated pathologies.

Here we focus on the current literature that demonstrates a role for DAMPs in driving chronic inflammation in RA. We will discuss the mechanistic differences between PAMP and DAMP mediated activation of TLRs; and highlight how these data have already informed novel pathways to develop improved therapies for RA and how future therapeutic strategies may further evolve. 


\section{The cellular basis of RA and current therapies}

$\mathrm{RA}$ is a systemic, chronic, progressive autoimmune inflammatory disease which affects approximately $1 \%$ of the population worldwide. The disease is polyarticular, and is characterised by synovitis, pannus formation, neovascularisation and hyperplasia caused by the infiltration of leukocytes. This in turn leads to the destruction of cartilage, tendon and bone, and the associated joint stiffness, swelling and pain that is the hallmark of this disease. Systemic symptoms also include inflammation in distil areas of the body, including the lungs, pericardium and pleura. Vasculitis, atherosclerosis, myocardial infarction and stroke are consequently commonly linked to RA.

The cells infiltrating the affected joint space are central to the pathology of RA, and include $\mathrm{B}$ cells, $\mathrm{T}$ cells, and cells of the monocyte/macrophage lineage as well as fibroblast-like synoviocytes. In their activated state within the affected joint these cells produce autoantibodies such as those against citrullinated proteins (CCP) and immunoglobulin (Rheumatoid factor (RF)), tissue degrading enzymes such as the matrix metalloproteaes (MMPs), as well as pro-inflammatory molecules such as TNF, Interleukin (IL)-6 and IL-1 that are central to tissue destruction, disease chronicity, and the maintenance of the inflammatory state. The ability of some cell types (B cells and RA synovial fibroblasts) to migrate to other sites has also been proposed as a precipitating event in the spread of disease to other joints (Lefevre et al., 2009).

\begin{tabular}{|c|c|c|c|}
\hline TARGET & NAME & FORM & STATUS \\
\hline $\begin{array}{l}\text { All rapidly } \\
\text { dividing cells }\end{array}$ & $\begin{array}{l}\text { Methotrexate } \\
\text { Other DMARDs eg } \\
\text { Sulphalazine, } \\
\text { Cyclosporin, } \\
\text { Corticosteriods }\end{array}$ & $\begin{array}{l}\text { Drugs (anti- } \\
\text { metabolites, anti- } \\
\text { inflammatory) }\end{array}$ & Clinical use \\
\hline$B$ cells & $\begin{array}{l}{ }^{1} \text { Rituximab (CD 20), } \\
\text { 2MDX-1342 (CD19), } \\
\text { 3anti-BAFF, 4anti- } \\
\text { CD16, 5Eculizumab } \\
\text { (complement C5), }\end{array}$ & $\begin{array}{l}\text { 1, 2, 5Humanised Ig, } \\
\text { 2human non- } \\
\text { glycosylated Ig, }\end{array}$ & $\begin{array}{l}\text { 1Clinical use } \\
\text { 2,3,4 Pre-clinical } \\
\text { 5Approved for } \\
\text { human use - not } \\
\text { RA }\end{array}$ \\
\hline T cells & Abatacept (CTLA4) & Fusion protein & Clinical use \\
\hline $\begin{array}{l}\text { Cytokines } \\
\text { 1-5TNF, 6IL- } \\
\text { 6R, 7IL-1, } \\
\text { 8VEGF }\end{array}$ & $\begin{array}{l}\text { 1Etanercept, } \\
\text { 2Adalimumab, } \\
\text { 3Infliximab, } \\
\text { "Golimumab, } \\
\text { 5Certolizumab, } \\
\text { 6Tocilizumab, } \\
\text { 7Anakinra, } \\
\text { 8Bevacizumab }\end{array}$ & $\begin{array}{l}\text { 1Fusion protein. } \\
\text { 2,4,5,6Human } \mathrm{Ig}, \\
{ }^{3} \text { chimeric } \\
\text { mouse/human Ig, } 7 \mathrm{IL}- \\
\text { 1R antagonist }\end{array}$ & Clinical use \\
\hline $\begin{array}{l}\text { Signalling } \\
\text { molecules } \\
\text { 1IKK2, 2PDE4, } \\
{ }^{3} \mathrm{p} 38,{ }^{4} \mathrm{Btk} \\
\text { 5Syk, 6JAK3 }\end{array}$ & $\begin{array}{l}\text { 1, 2,3 Multiple, } \\
\text { 4CG11746, 4PC132765, } \\
\text { 6CP-690550, 5R788 } \\
\text { (anti-Syk) }\end{array}$ & $\begin{array}{l}\text { Small molecule } \\
\text { inhibitors }\end{array}$ & Pre-clinical \\
\hline
\end{tabular}

Table 1. Current RA therapies 
Knowledge of the processes responsible for disease activity and progression has lead to significant advances in the treatment of RA in the last 30 years. Early treatment, within months of the onset of persistent symptoms, is recommended, and at the present time usually takes the form of disease modifying anti-rheumatic drugs (DMARD) such as methotrexate. In more recent years however, the choice of treatment for RA has expanded significantly, and importantly now utilises agents that are less globally immunosuppressive than methotrexate (Weinblatt et al., 1985) (Table 1). These newer therapies target either specific cell types, such as B and T cells that present within the inflamed synovium, or their products (Genovese et al., 2008; Tedder, 2009; Townsend et al., 2010; Buch et al., 2011). Indeed, anti-cytokine therapies have revolutionised the treatment of RA in recent years. In particular, the use of anti-TNF biologicals such as Adalimumab, Etanercept and Infliximab have become the treatment of choice in those who do not respond to conventional DMARDs (Taylor et al., 2009), although biologicals that target other pro-inflammatory cytokines are also approved for use. These include Tocilizumab (anti-IL-6R) (Fleischmann et al., 2006; Jones et al., 2010) and Anakinra, a recombinant IL-1 receptor antagonist, as well as Bevacizumab, an antibody that targets vascular endothelial growth factor (VEGF) and hence may reduce neovascularisation that pannus formation depends upon. A variety of small molecule inhibitors designed to target critical elements of the B cell receptor, $\mathrm{T}$ cell receptor or cytokine signalling pathways such as inhibitors of IKK2, PDE4 and Btk (Bruton's tyrosine kinase), have shown interesting results in some animal models of arthritis, as have clinical trials with the syk inhibitor R788 (Podolin et al., 2005; Lindstrom et al., 2010; Di Paolo et al., 2011). The p38 inhibitors however, which showed such promise in animal models have not lived up to expectations in clinical trials and have not progressed beyond phase II (Genovese, 2009).

Despite the significant advances made with this arsenal of therapies, the goal of achieving sustained remission of RA has remained elusive and even with long term DMARD and biologic therapy is relatively uncommon. The efficacy of treatments is also unpredictable. Thus, a significant proportion of patients do not respond adequately to first line DMARD treatment and are then moved on to biologics. Even here, approximately $40 \%$ of patients do not respond to anti-TNF therapy for example. Moreover, many of these treatments are accompanied by significant side-effects, ranging from injection site reactions, increased infection rates and neutropenia to the potential for an increased risk of malignancies (van Vollenhoven, 2009).

When taking a global view of all the therapies for RA, either in use in the clinic, in early trials, in animal models, or in in vitro studies, it becomes clear that all are designed to target the ongoing process of inflammation. Namely the cells present in the joint during the inflammatory process, or their soluble products (cytokines), rather than targeting a causative agent for RA. However, for RA sufferers a single causative agent has not, and probably will never, be defined. Rather, RA is a complex disease with a multi-factorial etiology. It's prevalence in women (3:1 female to male ratio) suggests a hormonal contribution, and there are clear links to environmental factors such as smoking as well as a predisposition to RA with certain HLA haplotypes (Bax et al., 2011). Genetic and twin studies also suggest a strong environmental influence as well as a genetic link. As a tractable causative agent or single predisposing gene is therefore unlikely to be identified, a therapy that will treat disease in the early stages, that will prevent progression to a chronic state and thereby allow the inflammatory state to resolve, thereby preventing tissue damage, bone and cartilage destruction and progression, remains the holy grail of many researchers. 
Given that RA is an inflammatory condition it is likely that a precipitating event initiates a state of inflammation. In the normal individual, inflammation is invariably initiated in response to danger signals sensed by a series of cellular receptors known as pattern recognition receptors (PRRs). PRRs were originally defined by their ability to recognise and respond to invading pathogens (bacterial, viral, fungal) but are now increasingly linked to the detection of damaged 'self' molecules known as DAMPs. A large body of evidence has emerged in the last decade implicating one particular family of PRRs, the TLRs, in driving inflammation during RA.

\section{The toll-like receptors}

TLRs are a highly conserved family of PRRs. With the most recent addition of murine TLR13 (Shi et al., 2011), 14 mammalian TLRs have been reported to date, with 10 human subtypes. All TLRs are type I transmembrane proteins comprising an extracellular domain of multiple leucine rich repeats (LRRs), a single membrane spanning $\alpha$-helix and a cytoplasmic Toll/IL1 receptor (TIR) homology signalling domain.

TLRs can be classified according to their subcellular localization: the endosomal TLRs 3, 7, 8 and 9 reside in intracellular compartments, whilst the others are found at the plasma membrane. This distribution also reflects the ligand specificity of TLRs; the cell surface receptors predominantly recognize pathogenic and self surface elements, whereas endosomal receptors primarily sense nucleic acids. Recognition of ligand triggers receptor dimerization which in turn triggers a multitude of signalling cascades leading to the expression of pro-inflammatory mediators such as cytokines and chemokines, which are designed to combat the perceived danger. In this way the body mounts an effective immune response (reviewed in (Piccinini et al., 2010). The TLR ligands that induce such a response include both PAMPs and DAMPs, and a more detailed list of them, with particular reference to those found in RA, can be found in Table 2. Thus, TLRs are critical for both the response to invading pathogens and the response to 'sterile' tissue damage.

\subsection{TLRs and RA pathology}

TLRs are expressed on a variety of different cell types, many of which are found within the inflamed rheumatoid joint, including myeloid cells, fibroblasts, epithelial and endothelial cells. In humans the first evidence linking the presence of TLRs with RA pathology arose from the comparison of TLR expression between normal or non-inflamed joints and RA joints. Significant up-regulation of a number of TLRs was observed in both synovial tissue and circulating immune cells isolated from RA patients. Table 3 depicts the specific pattern of expression of these TLRs in RA.

\begin{tabular}{|l|c|c|c|c|}
\hline TLR & PAMP & SOURCE & DAMP & SOURCE \\
\hline TLR1 & Triacyl lipoprotein & Bacteria & $\beta$-defensin 3 & $\begin{array}{c}\text { Released from } \\
\text { activated/necrotic } \\
\text { cells }\end{array}$ \\
\hline TLR2 & Lipoprotein & $\begin{array}{c}\text { Bacteria, } \\
\text { Viruses, } \\
\text { Parasites }\end{array}$ & $\begin{array}{c}\text { HSP60, 70, Gp96, HMGB1, } \\
\text { HMGB1-nucleosome } \\
\text { complexes, } \beta \text {-defensin 3, } \\
\text { surfactant proteins A and }\end{array}$ & $\begin{array}{c}\text { Released from } \\
\text { activated/necrotic } \\
\text { cells }\end{array}$ \\
\hline
\end{tabular}




\begin{tabular}{|c|c|c|c|c|}
\hline & & & $\begin{array}{c}\text { D, eosinophil derived } \\
\text { neurotoxin, } \\
\text { antiphospholipid } \\
\text { antibodies, serum amyloid } \\
\text { A,cardiac myosin, PAUF, } \\
\text { CEP, monosodium urate } \\
\text { crystals } \\
\text { Biglycan, versican } \\
\text { Hyaluronic acid fragments }\end{array}$ & $\begin{array}{c}\text { Induced upon tissue } \\
\text { damage } \\
\text { Degradation of } \\
\text { tissue }\end{array}$ \\
\hline TLR3 & dsRNA & Viruses & mRNA & $\begin{array}{c}\text { Released from } \\
\text { activated/necrotic } \\
\text { cells }\end{array}$ \\
\hline TLR4 & $\begin{array}{c}\text { Lipopolysaccharide } \\
\text { (LPS) }\end{array}$ & $\begin{array}{l}\text { Bacteria, } \\
\text { Viruses }\end{array}$ & $\begin{array}{c}\text { HMGB1, surfactant } \\
\text { proteins A and D, } \beta- \\
\text { defensin 2, HSP60, 70, 72, } \\
\text { 22, Gp96, S100A8, S100A9, } \\
\text { neutrophil elastase, } \\
\text { antiphospholipid } \\
\text { antibodies, lactoferrin, } \\
\text { serum amyloid A, oxidised } \\
\text { LDL, saturated fatty acids, } \\
\text { resistin, PAUF, } \\
\text { monosodium urate crystals } \\
\text { Biglycan, fibronectin EDA, } \\
\text { fibrinogen, tenascin-C } \\
\text { Heparin sulphate } \\
\text { fragments, hyaluronic acid } \\
\text { fragments }\end{array}$ & $\begin{array}{c}\text { Induced upon tissue } \\
\text { damage } \\
\begin{array}{c}\text { Degradation of } \\
\text { tissue }\end{array}\end{array}$ \\
\hline TLR5 & Flagellin & Bacteria & Unknown & Unknown \\
\hline TLR6 & Diacyl lipoprotein & $\begin{array}{c}\text { Bacteria, } \\
\text { Viruses }\end{array}$ & Unknown & Unknown \\
\hline TLR7/8 & ssRNA & $\begin{array}{l}\text { Bacteria, } \\
\text { Viruses }\end{array}$ & $\begin{array}{c}\text { Antiphospholipid } \\
\text { antibodies, ssRNA, cardiac } \\
\text { myosin }\end{array}$ & $\begin{array}{c}\text { Released from } \\
\text { activated/necrotic } \\
\text { cells }\end{array}$ \\
\hline TLR9 & CpG-DNA & $\begin{array}{l}\text { Bacteria, } \\
\text { Viruses, } \\
\text { Protazoa }\end{array}$ & $\begin{array}{l}\text { IgG-chromatin complexes, } \\
\text { mitochondrial DNA }\end{array}$ & $\begin{array}{c}\text { Released from } \\
\text { activated/necrotic } \\
\text { cells }\end{array}$ \\
\hline \begin{tabular}{|l|} 
TLR10 \\
\end{tabular} & Unknown & Unknown & Unknown & Unknown \\
\hline TLR11 & $\begin{array}{l}\text { Profilin-like } \\
\text { molecule }\end{array}$ & Protazoa & Unknown & Unknown \\
\hline
\end{tabular}

DAMPs in red have been reported in the RA joint.

Table 2. Exogenous and endogenous activators of human TLRs. 


\begin{tabular}{|c|c|c|c|}
\hline TLR & EXPRESSION & $\mathbf{F}$ & REFERENCE \\
\hline TLR1 & $\begin{array}{l}\text { Protein in DCs }>\text { macrophages }>\text { fibroblasts from RA } \\
\text { joint }\end{array}$ & nd & (Tamaki et al., 2011) \\
\hline \multirow[t]{5}{*}{ TLR2 } & $\begin{array}{l}\text { mRNA in RA synovial tissue, protein in DCs and } \\
\text { macrophages but not T cells or fibroblasts from RA } \\
\text { joint }\end{array}$ & yes & $\begin{array}{l}\text { (Sacre et al., 2007) } \\
\text { (Tamaki et al., 2011). }\end{array}$ \\
\hline & $\begin{array}{l}\text { mRNA in RA > OA or non arthritic joints, at synovial } \\
\text { lining, sites of attachment and invasion into cartilage } \\
\text { or bone, around small vessels and in areas of } \\
\text { infiltrating lymphocytes (fibroblasts not macrophages } \\
\text { or T cells) }\end{array}$ & yes & (Seibl et al., 2003) \\
\hline & $\begin{array}{l}\text { Protein in RA > OA or healthy joints in synovial } \\
\text { lining, sublining and perivascular regions }\end{array}$ & nd & $\begin{array}{l}\text { (Radstake et al., } \\
\text { 2004) }\end{array}$ \\
\hline & Protein in RA blood monocytes, tissue macrophages & yes & $\begin{array}{l}\text { (Iwahashi et al., } \\
\text { 2004; Huang et al., } \\
\text { 2007) }\end{array}$ \\
\hline & $\begin{array}{l}\text { Protein in fibroblasts from RA }>\text { OA joints }>\text { healthy } \\
\text { skin }\end{array}$ & yes & (Kim et al., 2007) \\
\hline \multirow[t]{2}{*}{ TLR3 } & $\begin{array}{l}\text { mRNA and protein in RA > OA or healthy synovium, } \\
\text { in fibroblasts of the synovial lining and sublining, } \\
\text { and in the perivascular areas }\end{array}$ & yes & $\begin{array}{l}\text { (Brentano et al., } \\
\text { 2005; Roelofs et al., } \\
\text { 2005) }\end{array}$ \\
\hline & $\begin{array}{l}\text { Protein in fibroblasts from early RA > OA or healthy } \\
\text { synovium }\end{array}$ & yes & (Ospelt et al., 2008) \\
\hline \multirow[t]{3}{*}{ TLR4 } & $\begin{array}{l}\text { mRNA in RA synovial tissue, protein in DCs and } \\
\text { macrophages but not T cells or fibroblasts from RA } \\
\text { joint }\end{array}$ & yes & $\begin{array}{l}\text { (Sacre et al., 2007) } \\
\text { (Tamaki et al., 2011) } \\
\text { (Huang et al., 2007) } \\
\end{array}$ \\
\hline & $\begin{array}{l}\text { Protein in synovial tissue from RA }>\text { OA }>\text { healthy } \\
\text { joints, in early and longstanding RA }\end{array}$ & yes & $\begin{array}{l}\text { (Radstake et al., } \\
\text { 2004) (Ospelt et al., } \\
\text { 2008) }\end{array}$ \\
\hline & Protein in RA synovial fibroblasts & yes & $\begin{array}{l}\text { (Kim et al., 2007; } \\
\text { Wu et al., 2010) }\end{array}$ \\
\hline TLR5 & $\begin{array}{l}\text { Protein in DCs }>\text { macrophages }>\text { fibroblasts from RA } \\
\text { joint }\end{array}$ & nd & (Tamaki et al., 2011) \\
\hline TLR6 & $\begin{array}{l}\text { Protein in DCs }>\text { macrophages }>\text { fibroblasts from RA } \\
\text { joint }\end{array}$ & nd & (Tamaki et al., 2011) \\
\hline TLR7 & Protein in RA synovium $>$ OA or healthy joints & yes & $\begin{array}{l}\text { (Roelofs et al., 2005; } \\
\text { Roelofs et al., 2009) }\end{array}$ \\
\hline TLR9 & $\begin{array}{l}\text { Protein in DCs }>\text { macrophages }>\text { fibroblasts from RA } \\
\text { joint }\end{array}$ & nd & (Tamaki et al., 2011) \\
\hline
\end{tabular}

nd $=$ not determined

$\mathrm{F}=$ function $=$ the ability of the TLR to respond to its cognate ligand in each cell/tissue type

Table 3. Distribution of TLR expression in the RA joint 
Further studies using ex vivo human disease models have provided evidence of a functional role for TLRs in driving inflammation in RA. Adenoviral over expression of dominant negative Myd88, an adaptor molecule required for signalling by all TLRs except TLR3, inhibited cytokine synthesis in RA synovial cells (Sacre et al., 2007). The naturally occurring TIR signalling antagonist single-immunoglobulin interleukin-1 receptor-related (SIGIRR) is also efficacious in suppressing cytokine synthesis in these cells (Drexler et al., 2010). Together these data suggest that TLRs may contribute to synovial inflammation but do not rule out the possibility that IL-1-mediated signalling, which shares the TIR-myd88 derived framework, is responsible for these findings, nor do they pinpoint any specific TLR.

\subsection{Which TLRs are important in RA?}

Evidence of a role in RA for both cell surface TLRs and endosomal TLRs in human disease is accumulating. In particular, over expression of dominant negative Mal, an adaptor protein required exclusively by TLR2 and 4 , has been shown to inhibit cytokine and protease synthesis in RA synovial cells, supporting the contribution of these two family members to the synthesis of pro-inflammatory mediators in the RA joint (Sacre et al., 2007). Blockade of the function of TLR2 and 4 using neutralizing antibodies has also been reported, and while commercially available antibodies to either TLR2 or TLR4 had no effect on cytokine production in isolated RA synovial cells at $10 \mu \mathrm{g} / \mathrm{ml}$ (Sacre et al., 2007), $1 \mu \mathrm{g} / \mathrm{ml}$ of an antiTLR2 antibody (OPN301) inhibited spontaneous cytokine release in RA tissue explants as effectively as anti-TNF antibodies (Nic An Ultaigh et al., 2011). Inhibition of TLR4 by the naturally occurring antagonist LPS isolated from Bartonella Quintana, also partially inhibited cytokine release in RA synovial biopsies (Abdollahi-Roodsaz et al., 2008). Stimulation of TLRs 2 , and 4 has also been shown to induce cytokine synthesis in cell cultures isolated from RA synovia (Sacre et al., 2008). While the same workers found that TLRs 7 and 9 were not responsive to their respective ligands in RA cultures, stimulation of TLRs 3 and 8 did increase cytokine production.

The contribution of endosomal TLRs to cytokine synthesis in RA is also supported by other studies; chloroquine, which prevents intracellular TLR function by inhibiting endosomal acidification, reduces cytokine release in synovial cells (Sacre et al., 2008). The selective serotonin reuptake inhibitors, antidepressant drugs fluoxetine and citalopram and the antidepressant small molecule mianserin are also efficacious in inhibiting synovial cell cytokine release (Sacre et al., 2010). These drugs also inhibit TLR3, $-7,-8$ and -9 activity, by mechanisms which are yet unknown. More specifically, the small molecule imiquimod, which targets TLR8, also inhibited the production of TNF from human RA synovial membranes (Sacre et al., 2008). There have also been anecdotal reports of improved symptoms in RA patients taking anti-depressants (Krishnadas et al., 2011). Taken together these studies suggest a significant role for TLR2 and 4 as well as the endosomal TLRs 3 and 8 in human disease.

\subsection{The role of TLRs in animal models of RA}

In addition to studies in human tissue, the contribution of TLRs to inflammation and joint destruction has been examined in rodent models of arthritis. Mice with targeted deletions in TLRs have demonstrated that specific family members are important in driving disease pathogenesis in vivo. 
Many experimental models of joint disease utilize TLR ligands to initiate or sustain disease induction, making interpretation of the contribution of each TLR to disease induction or progression difficult (Joosten et al., 2003; Frasnelli et al., 2005; Lee et al., 2005). However, in a serum transfer model where induction of arthritis occurs independently of TLR administration, disease was not sustained in TLR4 null mice (Choe et al., 2003). Likewise, the severity of spontaneous, IL-17 driven arthritis in mice lacking IL-1RA is significantly reduced when crossed with TLR4 null mice, concomitant with blunted expression of IL-17 suggesting a key role for TLR4. In this model TLR2 null mice showed increased disease severity whereas TLR9 knockout had no effect on disease (Abdollahi-Roodsaz et al., 2008).

Whilst most data point towards a role for TLR4 in disease progression in mice in vivo, recent data have also suggested a role for the endosomal TLRs. Fluoxetine and citalopram reduce disease progression in murine collagen induced arthritis (Sacre et al., 2010). TLR3 was found to be the most significantly up-regulated TLR during pristine induced arthritis in rats, where it appeared in the spleen early after disease initiation. Stimulation of TLR3 with polyI:C also exacerbated disease severity and silencing TLR3 expression reduced disease severity in these animals (Meng et al., 2010).

Despite evidence from human studies highlighting the contribution of TLR8 in synovial inflammation, the lack of activation of murine TLR8 by its cognate ligand suggests this PRR is not biologically active in mice (Heil et al., 2004). Nor is TLR10 present in mice (Hasan et al., 2005). This makes investigation of the in vivo function of these TLRs challenging. Combined with the fact that TLR signalling and gene activation is speciesspecific, notably most recently highlighted by examination of the differences in human and murine TLR4-mediated nickel recognition that confers contact hypersensitivity specifically to man (Schmidt et al., 2010), extrapolation of data between species should be undertaken cautiously.

\subsection{Targeting TLRs as a therapy in RA}

Studies examining the blockade of TLRs in mouse models have confirmed the importance of TLRs in disease and have provided evidence that TLR antagonism may be a viable means to reduce inflammation in RA. Treatment with LPS from Bartonella quintana and ST2 protein expressed by mast cells and T helper cell type 2 (Th2) inhibits TLR4-mediated signalling in experimental models of arthritis, resulting in disease amelioration (Leung et al., 2004; Abdollahi-Roodsaz et al., 2007). Further evidence for a role for the endosomal TLRs in CIA has also come from studies with short DNA oligonucleotides (ODNs). These act as Immunoregulatory Sequences (IRS) and inhibit endosomal TLR activity (Barrat et al., 2005; Ranjith-Kumar et al., 2008; Lenert, 2010). Prophylactic administration of ODNs in CIA and CpG-induced arthritis has been shown to abrogate disease progression (Zeuner et al., 2002; Dong et al., 2004).

In the light of the wealth of evidence implicating TLRs in both animal models of RA and in human disease considerable commercial, pharmaceutical activity has also been focused on designing TLR inhibitors for use in treating RA. TLR antagonists in preclinical development for RA include NI-0101, a TLR4 specific antibody developed by NovImmune, OPN305, a TLR2 specific antibody developed by Opsona, VTX-763, a small molecule inhibitor targeting TLR8 developed by VentiRx Pharmaceuticals and DV-1179, a DNA based TLR7/9 antagonist, developed by Dynavax. There are also several compounds currently in trial. For example, Heat shock protein 10 (HSP10) (chaperonin 10) which can inhibit LPS mediated 
TLR4 activation, has improved symptoms in all RA patients tested, causing disease remission in 3 out of 23 in a small clinical trial (Vanags et al., 2006). Cbio et al are also examining the recombinant analogue of HSP10, XToll@, in a phase II clinical trial for RA. The DNA-based TLR7/9 antagonist, IMO-3100, developed by Idera, has also shown promising results in vivo for several autoimmune disease models. Phase I clinical trials of IMO-3100 in healthy subjects are underway and it appears to be well tolerated with no major adverse effects; in addition to reducing the release of cytokines such as TNF and IL-1 in these subjects.

Taken together, data from human, animal and pharmaceutical studies suggests a significant role for TLRs 2 and 4, in addition to the endosomal TLRs in synovial inflammation, in RA. Intriguingly however, the identity of the factor or factors that mediate this activation is not clear.

\section{Which TLR activators drive chronic inflammation in RA?}

Infection has long been purported to be a key underlying factor in RA pathogenesis. However, whilst pathogenic stimuli may trigger inflammation in RA, a causative infectious agent for RA has not been found and there is little evidence to suggest that PAMPs generate sustained joint inflammation (Schumacher et al., 1999; Chen et al., 2003). In contrast, data implicating DAMPs in RA pathogenesis have emerged from a number of independent studies in which factors derived from the serum, synovial fluid or synovial cells of RA patients can activate TLR mediated signalling pathways (Brentano et al., 2005; Roelofs et al., 2005; Sacre et al., 2007).

DAMPs are endogenous molecules that are immunologically silent in healthy tissues but become active upon tissue injury. They include intracellular molecules released from necrotic cells or secreted from activated cells, extracellular matrix molecule fragments created by tissue damage or proteolysis and extracellular matrix molecules that are specifically expressed upon tissue injury. In normal circumstances they act as danger signals that alert the organism to tissue damage and initiate the process of tissue repair. In addition to this physiological role however, there is evidence which indicates that DAMPS also contribute to the pathogenesis of many inflammatory and autoimmune diseases characterized by aberrant TLR activation including RA.

High levels of some DAMPs are detected in the destructive milieu of the RA joint (Table 2) (reviewed in (Piccinini et al., 2010), where they are hypothesized to drive chronic inflammation by invoking a perpetual destructive cycle where inflammation leads to the creation of new stimulators of inflammation (Roelofs et al., 2008). A number of approaches have been taken to examine the effect of DAMP administration, deletion or blockade in animal models of arthritis and data supporting the role of specific molecules in such models are summarized in Table 4.

In particular, the administration of the fibronectin EDA domain (FNEDA), fibrinogen, HMGB-1 and tenascin-C intra-articularly to mice provokes pathological inflammation in vivo, (Pullerits et al., 2003; Gondokaryono et al., 2007; Midwood et al., 2009). Moreover, targeted deletion of tenascin-C protects mice from experimental disease; synovial inflammation is induced but is transient and little tissue destruction occurs in contrast to wild type mice (Midwood et al., 2009) suggesting that tenascin-C plays a crucial role in disease chronicity. 


\begin{tabular}{|l|l|l|}
\hline \multicolumn{1}{|c|}{ DAMP } & \multicolumn{1}{|c|}{ Effect of intra-articular administration in mice } & \multicolumn{1}{c|}{ Reference } \\
\hline Fibrinogen & $\begin{array}{l}\text { Induced joint inflammation that is inhibited by } \\
\text { CTLA4-Ig }\end{array}$ & $\begin{array}{l}\text { (Ho et al., 2010; Yue } \\
\text { et al., 2010) }\end{array}$ \\
\hline FNEDA & $\begin{array}{l}\text { Induced TLR4 dependent transient ankle } \\
\text { swelling, cytokine synthesis, synovial } \\
\text { inflammation }\end{array}$ & $\begin{array}{l}\text { (Gondokaryono et al., } \\
\text { 2007) }\end{array}$ \\
\hline HMGB1 & $\begin{array}{l}\text { Induced synovial inflammation, some pannus } \\
\text { formation }\end{array}$ & (Pullerits et al., 2003) \\
\hline Tenascin-C & $\begin{array}{l}\text { Induced TLR4 dependent joint inflammation and } \\
\text { tissue erosion }\end{array}$ & $\begin{array}{l}\text { (Midwood et al., } \\
\text { 2009) }\end{array}$ \\
\hline Effect of targeted deletion in mice & $\begin{array}{l}\text { Protected from persistent synovial inflammation, } \\
\text { joint erosion and tissue destruction in antigen } \\
\text { induced arthritis }\end{array}$ & $\begin{array}{l}\text { (Midwood et al., } \\
\text { 2009) }\end{array}$ \\
\hline HMBG1 & $\begin{array}{l}\text { Effect of blockade in murine disease model } \\
\text { Polyclonal antibodies or the DNA binding box A } \\
\text { disease in collagen induced arthritis }\end{array}$ & $\begin{array}{l}\text { (Andersson et al., } \\
\text { 2004) }\end{array}$ \\
\hline HSP90 & $\begin{array}{l}\text { SNX-7081 (inhibitor) ameliorated disease, joints } \\
\text { returned to normal in collagen induced arthritis }\end{array}$ & (Rice et al., 2008) \\
\hline $\begin{array}{l}\text { Neutrophil } \\
\text { elastase }\end{array}$ & $\begin{array}{l}\text { ONO-5046 (inhibitor) reduced incidence and } \\
\text { severity of disease, ablated cartilage destruction } \\
\text { in collagen induced arthritis }\end{array}$ & $\begin{array}{l}\text { (Kakimoto et al., } \\
\text { 1995) }\end{array}$ \\
\hline
\end{tabular}

Table 4. Evidence supporting the role of specific DAMPs in driving inflammation in RA

\section{The role of citrullination}

The mechanism underlying the switch from DAMPs that initiate controlled tissue repair, to those that mediate chronic, uncontrolled inflammation is still unclear, but recent evidence suggests that the process of citrullination may play a key role in this event. Citrullination is a post-translational event whereby peptidyl arginine deaminase enzymes convert arginine residues on susceptible molecules to citrulline.

Fibrinogen, a DAMP and TLR4 agonist, has been shown to be citrullinated in the RA joint (Sebbag et al., 2006; van Beers et al., 2010), which potentiates its activation of TLR4 and enhances its activity within immune complexes (Sokolove et al., 2011). Moreover, immunization with citrullinated, but not native, fibrinogen induces a $\mathrm{T}$ cell dependent murine arthritis (Ho et al., 2010; Yue et al., 2010). In addition, citrullination modifies the antigenicty of fibrinogen by creating new epitopes preferentially recognized by HLA DR (James et al., 2010). Whilst the accumulation of citrullinated proteins is a hallmark of many autoimmune diseases, unique to RA is the loss of tolerance to these epitopes. Anticitrullinated protein antibodies (ACPAs) are present in $\sim 65 \%$ of RA patients but are found in only $<1 \%$ of individuals who do not have RA. Appearing before any evident symptoms, they correlate with poor prognosis; progressive joint destruction and low remission (Scott et al., 2010). Largely used diagnostically, emerging evidence suggests that ACPAs actively contribute to disease pathogenesis as their adoptive transfer enhances experimental murine arthritis (Kuhn et al., 2006; Uysal et al., 2009). Investigation of which DAMPs are 
pathologically post translationally modified in this and other ways may reveal the antigens that drive autoimmunity; thereby shedding light on RA disease pathogenesis.

In summary therefore, the presence of DAMPs within the RA synovia or their elevated levels within the peripheral circulation of patients, implicates their involvement in disease pathology. This hypothesis is now underscored by evidence in animal models of RA that includes the effects on disease after targeted deletion of DAMPs, the induction of disease by administration of DAMPS as well as the manipulation of DAMP function / expression. However, whilst targeted deletion of a particular DAMP is possible in the mouse it is clearly not a viable therapeutic option in the clinic. A more achievable goal is to target the receptors or signalling pathways involved in DAMP activity, an approach that requires a detailed understanding of both.

\section{Distinct mechanisms of DAMP versus PAMP-mediated TLR activation}

Whilst there is now clear evidence for a role for endosomal TLRs -3 and -8 , their ligands are still to be defined; all DAMPS that have been implicated in RA to date mediate their effects via either TLR2 or 4 (Tables 2 and 4). However, despite considerable evidence implicating TLRs -2 and -4 in RA, there is also conflicting evidence. In particular, the inability of some function blocking antibodies to prevent spontaneous cytokine production in isolated RA synovial cells (Sacre et al., 2007), and the protective effect of TLR2 deletion in murine arthritis (Abdollahi-Roodsaz et al., 2008) might suggest that these TLRs are not important in RA. Moreover, SNPs of TLR2 and TLR4 or polymorphisms in human TLR4 that prevent LPS responsiveness do not correlate with RA disease susceptibility. For example, the Asp299Gly mutation in TLR4 (Kilding et al., 2003; Radstake et al., 2004) or Arg677Trp and Arg753Gln polymorphisms in TLR2 (Sanchez et al., 2004) that prevent PAMP induced activation of cells show no significant association with RA.

However, the apparent discordance with SNP data and some antibody studies may be accounted for by the idea that the mechanism of TLR activation by DAMPs is unlikely to be the same as that used by the pathogenic activation of TLRs. LPS-relevant SNPs and antibodies that prevent LPS-TLR4 association may therefore not be applicable to TLR4:DAMP association. Indeed, studies with HMGB1, HSPs and tenascin-C, all DAMPS that have been implicated in RA, have revealed differences in the gene expression profiles and cytokines produced by these DAMPs when compared to LPS. This disparity was despite the uniform use of the TLR4 receptor. Thus, whilst HMGB1 and LPS induce many of the same genes in neutrophils from septic patients, there are also distinct differences, in particular in the expression of IL-8 (Silva et al., 2007). HSP60 is able to induce IFN alpha production in peritoneal macrophages and bone marrow derived DCs where LPS cannot (Osterloh et al., 2007), and tenascin-C exhibits a different profile of cytokine induction in RA synovial fibroblasts to LPS, being unable to induce IL-8 in these cells (Midwood et al., 2009). The induction of different gene patterns implies that the DAMPS are using TLR4 in a different way from the PAMPs. This is perhaps not surprising when we consider that TLR4 recognises a wide variety of ligands, ranging from HSPs to lipids to breakdown products of the extracellular matrix (Piccinini et al., 2010) and it is unlikely that the TLR4 molecule would be able to recognise such a diverse repertoire of molecules in the same way. This is borne out by findings from crystallography studies which have revealed three basic mechanisms for TLR:PAMP association. Thus, the crystal structure of the extracellular domain of TLR3 complexed with ds RNA reveals that this molecule interacts directly with 
residues on the external surface of the TLR3 homodimer (Liu et al., 2008). More recent modelling of TLRs 7 and 9 also suggests direct ligand binding to the TLR molecule (Kubarenko et al., 2010). In contrast, TLR1:TLR2 hetero-dimerisation results in the formation of a hydrophobic pocket into which the lipopeptide PAM3Cys fits (Jin et al., 2007). Lastly, the structure of the TLR4:MD2:LPS complex reveals that LPS does not initially make direct contact with TLR4, but rather first binds to MD2, altering its conformation and allowing it to bind to and cause homodimerisation of TLR4 (Park et al., 2009). In this case, TLR4 residues important for LPS activity include those required for MD2 binding and those required for receptor homodimerisation. TLR4 responses to LPS also require the presence of CD14 which facilitates the transfer of LPS to MD2.

Our knowledge of the receptor complexes used by DAMPs is far from complete, but it is already clear that these molecules have a further level of complexity in their receptor organisation. Thus, of those that require TLR4, some, such as HSP70, biglycan and s100 also require both CD14 and MD2 for activity. Others, such as Gp96, HMGB1 and fibronectin EDA require only MD2, whilst another group that includes surfactant protein $\mathrm{A}$ and lactoferrin require only CD14 (Piccinini et al., 2010). The last, and probably the most diverse group of DAMPs use co-receptors or accessory molecules that are distinct from CD14 and MD2. Immune complexes of citrullinated fibrinogen for example have recently been shown to use a combination of Fcgamma receptors and TLR4 (Sokolove et al., 2011), and may also use CD11b/ CD18 (Barrera et al., 2011). A-SAA, which has been associated with RA and uses the TLR2 receptor has been shown to also use both CD36 and FPRL-1 as co-receptors, while low molecular weight hyaluronan forms complexes with TLR2 and CD44, and biglycan, which may use both TLR2 and TLR4, uses a variety of molecules including CD14, MD2, P2x4 and NLRP3 (Babelova et al., 2009). Other DAMPs such as tenascin-C do not use CD14 or MD2 (Midwood et al., 2009). Whether they bind directly to TLR4 or use an as yet undefined co-receptor molecule(s) is unclear at present.

Because of their alternative use of co-receptor molecules, DAMPs are therefore likely to use different residues on the TLR4 molecule than those used by LPS, so it may not be surprising that SNPs that affect LPS binding and antibodies designed to prevent LPS activation of TLR4 are inactive in RA where DAMP mediated activation of TLR4 may be critical to disease pathology. This hypothesis is confirmed by studies of the D299G and T399I mutations in TLR4. These have been shown to prevent LPS activation, but to enhance the ability of TLR4 to respond to fibrinogen. (Hodgkinson et al, 2008)

The signalling mechanisms used by DAMPs are also not well defined, and there is very little data available at present to suggest therapeutic targets for DAMPs. However, the use of TLR molecules suggests that many of the same pathways activated by PAMPs may be relevant. This has been confirmed by recent studies of oxidised LDL signalling (a TLR4 DAMP), which shows activation of many familiar pathways such as those involving IKK and the MAP kinases. Studies with tenascin-C also show that MyD88 signalling is important in response to this molecule (Midwood et al., 2009). Any differences between DAMP and LPS mediated signalling pathways are likely to come from the DAMP use of alternative co-receptors. Molecules such as CD36, CD44 and integrins already have defined signalling pathways. Whether DAMP signalling will prove to be simply a combination of TLR:MyD88 driven pathways and those emanating from any co-receptor molecules remains to be defined. It is more likely however, that the signal transduction mechanism of DAMPs will be a result of a combination of both pathways, where each is able to modulate / modify the other. 
Examples of other molecules able to modify TLR signalling pathways, and consequently TLR-induced cytokine production are already established in the literature, and in particular a number of molecules that contain ITAM motifs have been shown to modulate TLR signalling pathways (Ivashkiv, 2008). Some such as TREM1 appear to cooperate with TLR molecules, amplifying the production of pro-inflammatory cytokines (Bleharski et al., 2003) whilst others such as the Fc $\gamma \mathrm{R}$ and the CD300F molecule inhibit TLR signalling (Wang et al., 2010). Other cell surface molecules able to modulate TLR activity include the TAM (Tyro3, Axl, Mer) receptors and SIGIRR (Rothlin et al., 2007; Drexler et al., 2010). The mechanisms responsible for these activities are varied and include ITAM mediated changes in IL-10 production and the induction of inhibitory signalling molecules. Conversely, recent data has emerged detailing a requirement for TLR4 in CD16 signalling revealing that TLRs in their turn can modulate other signalling pathways (Rittirsch et al., 2009).

\section{Conclusion}

In conclusion, it is clear that whilst the advent of specific biological therapies for the treatment of RA has significantly improved treatment of this disease in the last 10 years, there is still a significant un-met clinical need for therapies that target the cause of disease chronicity rather than its consequences.

Increasing evidence from in vitro studies, murine models of disease, and human studies, suggests that the TLRs play a significant role in RA. In particular, TLRs 2 and 4 and the intracellular TLRs 3 and 8 are increasingly regarded as key to the pathogenesis of this disease. However, PAMPs derived from infectious agents are not found in RA joints and are unlikely to be the causative TLR ligands in RA. Rather, there is now increasing evidence that endogenously derived DAMPs, either in their native form or in a citrullinated state, are able to drive the chronicity of RA. DAMPs comprise an enormously diverse subset of molecules and targeting them as a form of RA therapy could be achieved in a number of different ways. Many of these approaches have already found some success in other fields, but have yet to be tested in RA.

For example, for DAMPs whose expression is specifically up-regulated during inflammation it may be possible to manipulate this induction of expression at the genetic level. This approach has been taken in a murine lung carcinoma model where knockdown of versican expression in Lewis lung carcinoma cell lines (LLC) ablated their tumorigenic capability, promoting mouse survival and reduced metastasis. Conversely, over expression of versican in LLC lines with low innate metastatic potential increased lung metastasis (Kim et al., 2009).

The use of micro RNAs (miRNAs) to manipulate gene expression is also attracting considerable attention. MicroRNAs are endogenous RNAs that post-transcriptionally modulate gene expression (reviewed in (Guo et al., 2010). Not surprisingly, regulation of gene expression by microRNAs has also been extended to the TLR signalling paradigm (reviewed in (O'Neill et al., 2011)) where they impose several levels of regulation on the TLR signalling axis. For example, miR-155, miR-21 and miR-147 regulate the expression of TLRs 2-4, downstream signalling mediators such as MyD88 and TRIF, as well as transcription factors NF-kB and IRF3 (reviewed in (O'Neill et al., 2011)). Recent studies have reported that miR-155, miR-146a and miR-203 are upregulated in RA synovial fibroblasts, resulting in altered cytokine and MMP synthesis (Stanczyk et al., 2008; Li et al., 2010; Stanczyk et al., 2011). These insights may create a novel approach to limiting excessive TLR activation during inflammation. 
A second method of modulating DAMP activity in RA may be to block their production or level of expression. Indeed, ethyl pyruvate, stearoyl lysophosphatidylcholine and nicotine have already been shown to be efficacious in ameliorating experimental sepsis by preventing HMGB1 release (Ulloa et al., 2003; Wang et al., 2004; Chen et al., 2005). However, the mechanism by which they do so is unclear and these compounds are likely also to affect numerous other cell processes. HMGB1 is released from cells by two distinct mechanisms: it is either liberated from cells undergoing necrosis (Scaffidi et al., 2002), or it is hyperacetylated and then actively secreted from stimulated cells. Other DAMPs including the S100 proteins are also secreted in the same way (Foell et al., 2007) and targeting this pathway therefore may potentially offer a means to modulate the release of intracellular DAMPs. Other DAMPs are generated by the degradation of extracellular matrix and inhibition of this process may also be therapeutically beneficial. This has already been tested in the case of immune stimulatory heparin sulphate (HS) fragments which are released from the ECM as a result of elastase activity (Brunn et al., 2005). Injection of elastase into the peritoneal cavity of mice caused the release of HS and induced sepsis, nearly as effectively as direct injection of HS or LPS (Johnson et al., 2004). Thus therapeutic measures aimed at

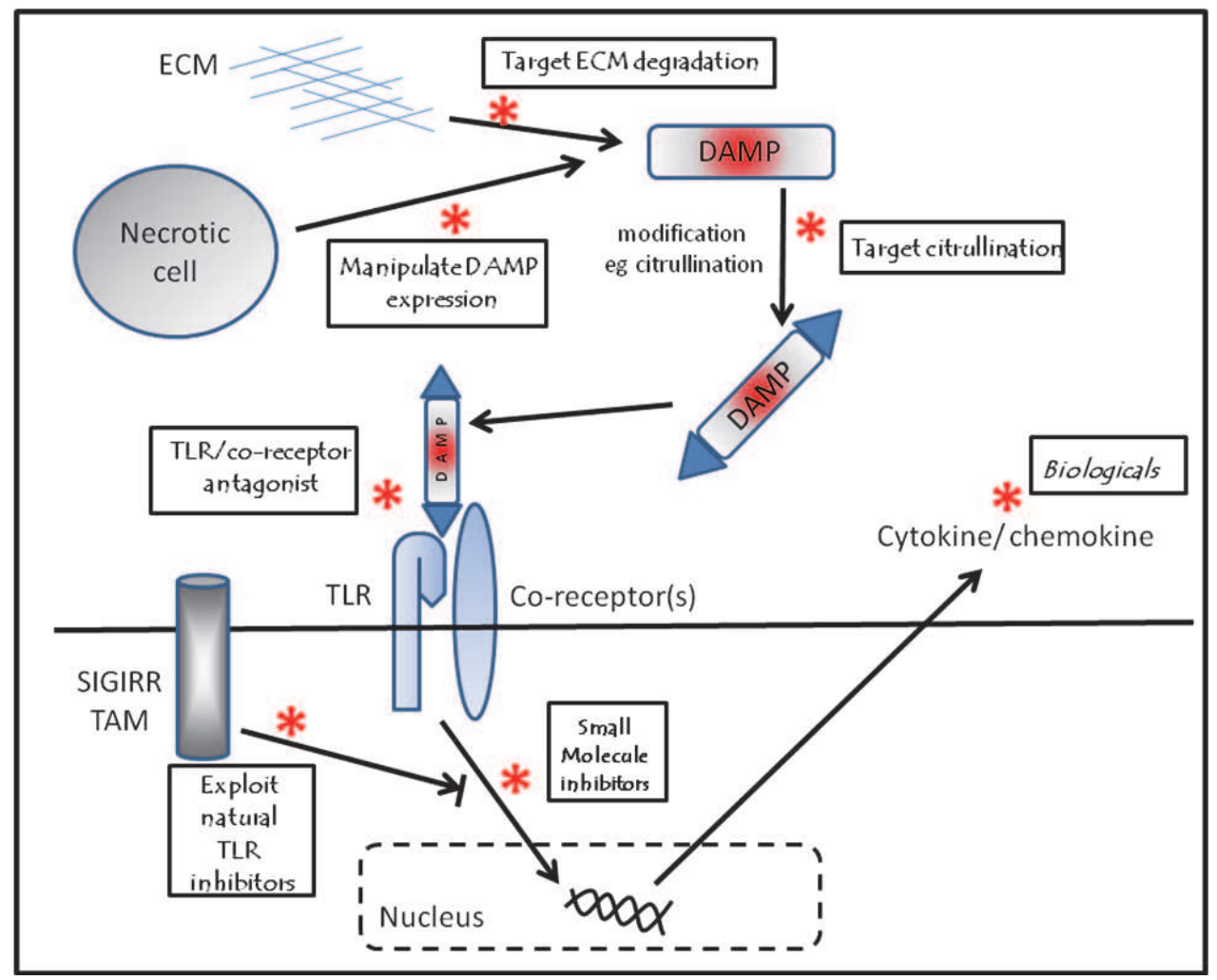

Red star $=$ Potential site of DAMP manipulation.

Fig. 1. Potential sites at which DAMP activity could be modulated for therapeutic advantage. 
blocking elastase could reduce the production of endogenous TLR4 activators. Indeed, pretreatment with neutrophil elastase inhibitor before induction of hepatic ischemiareperfusion injury has already been shown to ameliorate liver damage (Uchida et al., 2009). Thirdly, as we have discussed here, targeting the TLRs that are critical for DAMP recognition is increasingly considered as a viable therapeutic option in RA. This can take the form of agents that antagonise DAMP:TLR association as has been tested with the antagonistic TLR2 and TLR4 antibody studies and the DNA based TLR7/9 antagonist IMO3100 and with the studies on Bartonella Quintana LPS and the ST2 protein. Other approaches tested so far include the use of antagonistic bent oligonucleotides that have a high affinity for HMGB1 and suppress HMGB1-induced proliferation and migration of smooth muscle cells in vitro (Musumeci et al., 2007). An engineered mutant fragment of HMGB1 (HMGB1 Mut (102-105)) that carries two glycine substitutions has also been shown to decrease TNF release induced by the full-length HMGB1 protein in human monocyte cultures (Yuan et al., 2008). In addition, the $\mathrm{N}$-terminal domain of thrombomodulin, an endothelial anticoagulant cofactor, has been shown to exert anti-inflammatory effects in a model of lethal endotoxemia partly by binding to and sequestering HMGB1 (Abeyama et al., 2005). Targeting the DAMP co-receptor molecules may also prove to be a viable therapeutic approach.

TLR signalling pathways, activated during DAMP recognition, would also represent tractable targets in RA and the success in in vitro studies and animal models of RA of small molecule inhibitors directed against signalling molecules such as p38, IKK2, PDE4, Syk and Btk may in large part be due to their effect on DAMP mediated signalling pathways. In addition, it will be interesting to see if DAMP-mediated signalling pathways are subject to the same control mechanisms as PAMP-mediated TLR signals. The role of naturally occurring molecules such as SIGIRR and SARM which are reported to modulate TLR signalling, as are the TAM receptors Tyro3, Axl and Mer. Many of these have not been examined in the context of DAMP:TLR activity and may yield further areas of study.

In summary, it is now clear that the TLR:DAMP axis represents a key point in RA pathology that will be susceptible to therapeutic attack. However, in order to mount such an attack we need to understand a number of key points: which DAMPs are relevant to RA pathology?; how are these DAMPs produced and / or modulated to become pathogenic?; how do the TLRs recognise DAMPs, including the role of co-receptor molecules?; and which signals are generated? The field of DAMP research in RA should prove to be an exciting one for many years.

\section{Acknowledgements}

The authors are supported by funding from Arthritis Research UK.

\section{References}

"www.opsona.com."

Abdollahi-Roodsaz, S., L. A. Joosten, et al. (2008). "Shift from toll-like receptor 2 (TLR-2) toward TLR-4 dependency in the erosive stage of chronic streptococcal cell wall arthritis coincident with TLR-4-mediated interleukin-17 production." Arthritis Rheum 58(12): 3753-3764. 
Abdollahi-Roodsaz, S., L. A. Joosten, et al. (2008). "Stimulation of TLR2 and TLR4 differentially skews the balance of $\mathrm{T}$ cells in a mouse model of arthritis." J Clin Invest 118(1): 205-216.

Abdollahi-Roodsaz, S., L. A. Joosten, et al. (2007). "Inhibition of Toll-like receptor 4 breaks the inflammatory loop in autoimmune destructive arthritis." Arthritis Rheum 56(9): 2957-2967.

Abeyama, K., D. M. Stern, et al. (2005). "The N-terminal domain of thrombomodulin sequesters high-mobility group-B1 protein, a novel antiinflammatory mechanism." J Clin Invest 115(5): 1267-1274.

Andersson, U. and H. Erlandsson-Harris (2004). "HMGB1 is a potent trigger of arthritis." J Intern Med 255(3): 344-350.

Babelova, A., K. Moreth, et al. (2009). "Biglycan, a danger signal that activates the NLRP3 inflammasome via toll-like and P2X receptors." J Biol Chem 284(36): 24035-24048.

Barrat, F. J., T. Meeker, et al. (2005). "Nucleic acids of mammalian origin can act as endogenous ligands for Toll-like receptors and may promote systemic lupus erythematosus." J Exp Med 202(8): 1131-1139.

Barrera, V., O. A. Skorokhod, et al. (2011). "Host fibrinogen stably bound to hemozoin rapidly activates monocytes via TLR-4 and CD11b/CD18-integrin: a new paradigm of hemozoin action." Blood 117(21): 5674-5682.

Bax, M., J. van Heemst, et al. (2011). "Genetics of rheumatoid arthritis: what have we learned?" Immunogenetics.

Bleharski, J. R., V. Kiessler, et al. (2003). "A role for triggering receptor expressed on myeloid cells- 1 in host defense during the early-induced and adaptive phases of the immune response." J Immunol 170(7): 3812-3818.

Brentano, F., O. Schorr, et al. (2005). "RNA released from necrotic synovial fluid cells activates rheumatoid arthritis synovial fibroblasts via Toll-like receptor 3." Arthritis Rheum 52(9): 2656-2665.

Brunn, G. J., M. K. Bungum, et al. (2005). "Conditional signaling by Toll-like receptor 4." FASEB J 19(7): 872-874.

Buch, M. H., J. S. Smolen, et al. (2011). "Updated consensus statement on the use of rituximab in patients with rheumatoid arthritis." Ann Rheum Dis 70(6): 909-920.

Chen, G., J. Li, et al. (2005). "Suppression of HMGB1 release by stearoyl lysophosphatidylcholine:an additional mechanism for its therapeutic effects in experimental sepsis." J Lipid Res 46(4): 623-627.

Chen, T., M. Rimpilainen, et al. (2003). "Bacterial components in the synovial tissue of patients with advanced rheumatoid arthritis or osteoarthritis: analysis with gas chromatography-mass spectrometry and pan-bacterial polymerase chain reaction." Arthritis Rheum 49(3): 328-334.

Choe, J. Y., B. Crain, et al. (2003). "Interleukin 1 receptor dependence of serum transferred arthritis can be circumvented by toll-like receptor 4 signaling." J Exp Med 197(4): 537-542.

Di Paolo, J. A., T. Huang, et al. (2011). "Specific Btk inhibition suppresses B cell- and myeloid cell-mediated arthritis." Nat Chem Biol 7(1): 41-50.

Dong, L., S. Ito, et al. (2004). "Suppressive oligonucleotides protect against collagen-induced arthritis in mice." Arthritis Rheum 50(5): 1686-1689. 
Drexler, S. K., P. Kong, et al. (2010). "SIGIRR/TIR-8 is an inhibitor of Toll-like receptor signaling in primary human cells and regulates inflammation in models of rheumatoid arthritis." Arthritis Rheum 62(8): 2249-2261.

Fleischmann, R. M., J. Tesser, et al. (2006). "Safety of extended treatment with anakinra in patients with rheumatoid arthritis." Ann Rheum Dis 65(8): 1006-1012.

Foell, D., H. Wittkowski, et al. (2007). "Mechanisms of disease: a 'DAMP' view of inflammatory arthritis." Nat Clin Pract Rheumatol 3(7): 382-390.

Frasnelli, M. E., D. Tarussio, et al. (2005). "TLR2 modulates inflammation in zymosaninduced arthritis in mice." Arthritis Res Ther 7(2): R370-379.

Genovese, M. C. (2009). "Inhibition of p38: has the fat lady sung?" Arthritis Rheum 60(2): 317320.

Genovese, M. C., M. Schiff, et al. (2008). "Efficacy and safety of the selective co-stimulation modulator abatacept following 2 years of treatment in patients with rheumatoid arthritis and an inadequate response to anti-tumour necrosis factor therapy." Ann Rheum Dis 67(4): 547-554.

Gondokaryono, S. P., H. Ushio, et al. (2007). "The extra domain A of fibronectin stimulates murine mast cells via toll-like receptor 4." J Leukoc Biol 82(3): 657-665.

Guo, H., N. T. Ingolia, et al. (2010). "Mammalian microRNAs predominantly act to decrease target mRNA levels." Nature 466(7308): 835-840.

Hasan, U., C. Chaffois, et al. (2005). "Human TLR10 is a functional receptor, expressed by B cells and plasmacytoid dendritic cells, which activates gene transcription through MyD88." J Immunol 174(5): 2942-2950.

Heil, F., H. Hemmi, et al. (2004). "Species-specific recognition of single-stranded RNA via toll-like receptor 7 and 8." Science 303(5663): 1526-1529.

Ho, P. P., L. Y. Lee, et al. (2010). "Autoimmunity against fibrinogen mediates inflammatory arthritis in mice." J Immunol 184(1): 379-390.

Hodgkinson, C.P. and Patel. K. et al. (2008). "Functional Toll-like receptor 4 mutations modulate the response to fibrinogen." Thromb Haemost. 100(2): 301-307.

Huang, Q., Y. Ma, et al. (2007). "Increased macrophage activation mediated through toll-like receptors in rheumatoid arthritis." Arthritis Rheum 56(7): 2192-2201.

Ivashkiv, L. B. (2008). "A signal-switch hypothesis for cross-regulation of cytokine and TLR signalling pathways." Nat Rev Immunol 8(10): 816-822.

Iwahashi, M., M. Yamamura, et al. (2004). "Expression of Toll-like receptor 2 on CD16+ blood monocytes and synovial tissue macrophages in rheumatoid arthritis." Arthritis Rheum 50(5): 1457-1467.

James, E. A., A. K. Moustakas, et al. (2010). "HLA-DR1001 presents "altered-self" peptides derived from joint-associated proteins by accepting citrulline in three of its binding pockets." Arthritis Rheum 62(10): 2909-2918.

Jin, M. S., S. E. Kim, et al. (2007). "Crystal structure of the TLR1-TLR2 heterodimer induced by binding of a tri-acylated lipopeptide." Cell 130(6): 1071-1082.

Johnson, G. B., G. J. Brunn, et al. (2004). "Cutting edge: an endogenous pathway to systemic inflammatory response syndrome (SIRS)-like reactions through Toll-like receptor 4." J Immunol 172(1): 20-24.

Jones, G. and C. Ding (2010). "Tocilizumab: a review of its safety and efficacy in rheumatoid arthritis." Clin Med Insights Arthritis Musculoskelet Disord 3: 81-89. 
Joosten, L. A., M. I. Koenders, et al. (2003). "Toll-like receptor 2 pathway drives streptococcal cell wall-induced joint inflammation: critical role of myeloid differentiation factor 88." J Immunol 171(11): 6145-6153.

Kakimoto, K., A. Matsukawa, et al. (1995). "Suppressive effect of a neutrophil elastase inhibitor on the development of collagen-induced arthritis." Cell Immunol 165(1): 2632.

Kilding, R., M. Akil, et al. (2003). "A biologically important single nucleotide polymorphism within the toll-like receptor-4 gene is not associated with rheumatoid arthritis." Clin Exp Rheumatol 21(3): 340-342.

Kim, K. W., M. L. Cho, et al. (2007). "Human rheumatoid synovial fibroblasts promote osteoclastogenic activity by activating RANKL via TLR-2 and TLR-4 activation." Immunol Lett 110(1): 54-64.

Kim, S., H. Takahashi, et al. (2009). "Carcinoma-produced factors activate myeloid cells through TLR2 to stimulate metastasis." Nature 457(7225): 102-106.

Krishnadas, R. and J. Cavanagh (2011). "Sustained remission of rheumatoid arthritis with a specific serotonin reuptake inhibitor antidepressant: a case report and review of the literature." J Med Case Reports 5: 112.

Kubarenko, A. V., S. Ranjan, et al. (2010). "Comprehensive modeling and functional analysis of Toll-like receptor ligand-recognition domains." Protein Sci 19(3): 558-569.

Kuhn, K. A., L. Kulik, et al. (2006). "Antibodies against citrullinated proteins enhance tissue injury in experimental autoimmune arthritis." J Clin Invest 116(4): 961-973.

Lang, K. S., M. Recher, et al. (2005). "Toll-like receptor engagement converts T-cell autoreactivity into overt autoimmune disease." Nat Med 11(2): 138-145.

Lartigue, A., P. Courville, et al. (2006). "Role of TLR9 in anti-nucleosome and anti-DNA antibody production in lpr mutation-induced murine lupus." J Immunol 177(2): 1349-1354.

Leadbetter, E. A., I. R. Rifkin, et al. (2002). "Chromatin-IgG complexes activate B cells by dual engagement of IgM and Toll-like receptors." Nature 416(6881): 603-607.

Lee, E. K., S. M. Kang, et al. (2005). "Essential roles of Toll-like receptor-4 signaling in arthritis induced by type II collagen antibody and LPS." Int Immunol 17(3): 325-333.

Lefevre, S., A. Knedla, et al. (2009). "Synovial fibroblasts spread rheumatoid arthritis to unaffected joints." Nat Med 15(12): 1414-1420.

Lenert, P. S. (2010). "Classification, mechanisms of action, and therapeutic applications of inhibitory oligonucleotides for Toll-like receptors (TLR) 7 and 9." Mediators Inflamm 2010: 986596.

Leung, B. P., D. Xu, et al. (2004). "A novel therapy of murine collagen-induced arthritis with soluble T1/ST2." J Immunol 173(1): 145-150.

Li, J., Y. Wan, et al. (2010). "Altered microRNA expression profile with miR-146a upregulation in CD4+ T cells from patients with rheumatoid arthritis." Arthritis Res Ther 12(3): R81.

Lindstrom, T. M. and W. H. Robinson (2010). "A multitude of kinases--which are the best targets in treating rheumatoid arthritis?" Rheum Dis Clin North Am 36(2): 367-383.

Liu, L., I. Botos, et al. (2008). "Structural basis of toll-like receptor 3 signaling with doublestranded RNA." Science 320(5874): 379-381. 
Meng, L., W. Zhu, et al. (2010). "Toll-like receptor 3 upregulation in macrophages participates in the initiation and maintenance of pristane-induced arthritis in rats." Arthritis Res Ther 12(3): R103.

Midwood, K., S. Sacre, et al. (2009). "Tenascin-C is an endogenous activator of Toll-like receptor 4 that is essential for maintaining inflammation in arthritic joint disease." Nat Med 15(7): 774-780.

Musumeci, D., G. N. Roviello, et al. (2007). "Bent oligonucleotide duplexes as HMGB1 inhibitors: a comparative study." Nucleosides Nucleotides Nucleic Acids 26(10-12): 1447-1450.

Nic An Ultaigh, S., T. P. Saber, et al. (2011). "Blockade of Toll-like receptor 2 prevents spontaneous cytokine release from rheumatoid arthritis ex vivo synovial explant cultures." Arthritis Res Ther 13(1): R33.

O'Neill, L. A., F. J. Sheedy, et al. (2011). "MicroRNAs: the fine-tuners of Toll-like receptor signalling." Nat Rev Immunol 11(3): 163-175.

Ospelt, C., F. Brentano, et al. (2008). "Overexpression of toll-like receptors 3 and 4 in synovial tissue from patients with early rheumatoid arthritis: toll-like receptor expression in early and longstanding arthritis." Arthritis Rheum 58(12): 3684-3692.

Osterloh, A., U. Kalinke, et al. (2007). "Synergistic and differential modulation of immune responses by Hsp60 and lipopolysaccharide." J Biol Chem 282(7): 4669-4680.

Park, B. S., D. H. Song, et al. (2009). "The structural basis of lipopolysaccharide recognition by the TLR4-MD-2 complex." Nature 458(7242): 1191-1195.

Piccinini, A. M. and K. S. Midwood (2010). "DAMPening inflammation by modulating TLR signalling." Mediators Inflamm 2010.

Podolin, P. L., J. F. Callahan, et al. (2005). "Attenuation of murine collagen-induced arthritis by a novel, potent, selective small molecule inhibitor of IkappaB Kinase 2, TPCA-1 (2-[(aminocarbonyl)amino]-5-(4-fluorophenyl)-3-thiophenecarboxamide), occurs via reduction of proinflammatory cytokines and antigen-induced $\mathrm{T}$ cell Proliferation." J Pharmacol Exp Ther 312(1): 373-381.

Pullerits, R., I. M. Jonsson, et al. (2003). "High mobility group box chromosomal protein 1, a DNA binding cytokine, induces arthritis." Arthritis Rheum 48(6): 1693-1700.

Radstake, T. R., B. Franke, et al. (2004). "The Toll-like receptor 4 Asp299Gly functional variant is associated with decreased rheumatoid arthritis disease susceptibility but does not influence disease severity and/or outcome." Arthritis Rheum 50(3): 9991001.

Radstake, T. R., M. F. Roelofs, et al. (2004). "Expression of toll-like receptors 2 and 4 in rheumatoid synovial tissue and regulation by proinflammatory cytokines interleukin-12 and interleukin-18 via interferon-gamma." Arthritis Rheum 50(12): 3856-3865.

Ranjith-Kumar, C. T., K. E. Duffy, et al. (2008). "Single-stranded oligonucleotides can inhibit cytokine production induced by human toll-like receptor 3." Mol Cell Biol 28(14): 4507-4519.

Rice, J. W., J. M. Veal, et al. (2008). "Small molecule inhibitors of Hsp90 potently affect inflammatory disease pathways and exhibit activity in models of rheumatoid arthritis." Arthritis Rheum 58(12): 3765-3775.

Rittirsch, D., M. A. Flierl, et al. (2009). "Cross-talk between TLR4 and FcgammaReceptorIII (CD16) pathways." PLoS Pathog 5(6): e1000464. 
Roelofs, M. F., S. Abdollahi-Roodsaz, et al. (2008). "The orchestra of Toll-like receptors and their potential role in frequently occurring rheumatic conditions." Arthritis Rheum 58(2): 338-348.

Roelofs, M. F., L. A. Joosten, et al. (2005). "The expression of toll-like receptors 3 and 7 in rheumatoid arthritis synovium is increased and costimulation of toll-like receptors 3,4 , and $7 / 8$ results in synergistic cytokine production by dendritic cells." Arthritis Rheum 52(8): 2313-2322.

Roelofs, M. F., M. H. Wenink, et al. (2009). "Type I interferons might form the link between Toll-like receptor (TLR) $3 / 7$ and TLR4-mediated synovial inflammation in rheumatoid arthritis (RA)." Ann Rheum Dis 68(9): 1486-1493.

Rothlin, C. V., S. Ghosh, et al. (2007). "TAM receptors are pleiotropic inhibitors of the innate immune response." Cell 131(6): 1124-1136.

Sacre, S., M. Medghalchi, et al. (2010). "Fluoxetine and citalopram exhibit potent antiinflammatory activity in human and murine models of rheumatoid arthritis and inhibit toll-like receptors." Arthritis Rheum 62(3): 683-693.

Sacre, S. M., E. Andreakos, et al. (2007). "The Toll-like receptor adaptor proteins MyD88 and $\mathrm{Mal} / \mathrm{TIRAP}$ contribute to the inflammatory and destructive processes in a human model of rheumatoid arthritis." Am J Pathol 170(2): 518-525.

Sacre, S. M., S. K. Drexler, et al. (2007). "Could toll-like receptors provide a missing link in chronic inflammation in rheumatoid arthritis? Lessons from a study on human rheumatoid tissue." Ann Rheum Dis 66 Suppl 3: iii81-86.

Sacre, S. M., A. Lo, et al. (2008). "Inhibitors of TLR8 reduce TNF production from human rheumatoid synovial membrane cultures." J Immunol 181(11): 8002-8009.

Sanchez, E., G. Orozco, et al. (2004). "Polymorphisms of toll-like receptor 2 and 4 genes in rheumatoid arthritis and systemic lupus erythematosus." Tissue Antigens 63(1): 5457.

Scaffidi, P., T. Misteli, et al. (2002). "Release of chromatin protein HMGB1 by necrotic cells triggers inflammation." Nature 418(6894): 191-195.

Schmidt, M., B. Raghavan, et al. (2010). "Crucial role for human Toll-like receptor 4 in the development of contact allergy to nickel." Nat Immunol 11(9): 814-819.

Schumacher, H. R., Jr., T. Arayssi, et al. (1999). "Chlamydia trachomatis nucleic acids can be found in the synovium of some asymptomatic subjects." Arthritis Rheum 42(6): 12811284.

Scott, D. L., F. Wolfe, et al. (2010). "Rheumatoid arthritis." Lancet 376(9746): 1094-1108.

Sebbag, M., N. Moinard, et al. (2006). "Epitopes of human fibrin recognized by the rheumatoid arthritis-specific autoantibodies to citrullinated proteins." Eur J Immunol 36(8): 2250-2263.

Seibl, R., T. Birchler, et al. (2003). "Expression and regulation of Toll-like receptor 2 in rheumatoid arthritis synovium." Am J Pathol 162(4): 1221-1227.

Shi, Z., Z. Cai, et al. (2011). "A novel Toll-like receptor that recognizes vesicular stomatitis virus." J Biol Chem 286(6): 4517-4524.

Silva, E., J. Arcaroli, et al. (2007). "HMGB1 and LPS induce distinct patterns of gene expression and activation in neutrophils from patients with sepsis-induced acute lung injury." Intensive Care Med 33(10): 1829-1839. 
Sokolove, J., X. Zhao, et al. (2011). "Immune complexes containing citrullinated fibrinogen costimulate macrophages via Toll-like receptor 4 and Fcgamma receptor." Arthritis Rheum 63(1): 53-62.

Stanczyk, J., C. Ospelt, et al. (2011). "Altered expression of microRNA-203 in rheumatoid arthritis synovial fibroblasts and its role in fibroblast activation." Arthritis Rheum 63(2): 373-381.

Stanczyk, J., D. M. Pedrioli, et al. (2008). "Altered expression of MicroRNA in synovial fibroblasts and synovial tissue in rheumatoid arthritis." Arthritis Rheum 58(4): 10011009.

Tamaki, Y., Y. Takakubo, et al. (2011). "Expression of Toll-like Receptors and Their Signaling Pathways in Rheumatoid Synovitis." J Rheumatol 38(5): 810-820.

Taylor, P. C. and M. Feldmann (2009). "Anti-TNF biologic agents: still the therapy of choice for rheumatoid arthritis." Nat Rev Rheumatol 5(10): 578-582.

Tedder, T. F. (2009). "CD19: a promising B cell target for rheumatoid arthritis." Nat Rev Rheumatol 5(10): 572-577.

Townsend, M. J., J. G. Monroe, et al. (2010). "B-cell targeted therapies in human autoimmune diseases: an updated perspective." Immunol Rev 237(1): 264-283.

Uchida, Y., M. C. Freitas, et al. (2009). "The inhibition of neutrophil elastase ameliorates mouse liver damage due to ischemia and reperfusion." Liver Transpl 15(8): 939-947.

Ulloa, L., F. M. Batliwalla, et al. (2003). "High mobility group box chromosomal protein 1 as a nuclear protein, cytokine, and potential therapeutic target in arthritis." Arthritis Rheum 48(4): 876-881.

Uysal, H., R. Bockermann, et al. (2009). "Structure and pathogenicity of antibodies specific for citrullinated collagen type II in experimental arthritis." J Exp Med 206(2): 449462.

van Beers, J. J., R. Raijmakers, et al. (2010). "Mapping of citrullinated fibrinogen B-cell epitopes in rheumatoid arthritis by imaging surface plasmon resonance." Arthritis Res Ther 12(6): R219.

van Vollenhoven, R. F. (2009). "Treatment of rheumatoid arthritis: state of the art 2009." Nat Rev Rheumatol 5(10): 531-541.

Vanags, D., B. Williams, et al. (2006). "Therapeutic efficacy and safety of chaperonin 10 in patients with rheumatoid arthritis: a double-blind randomised trial." Lancet 368(9538): 855-863.

Wang, H., H. Liao, et al. (2004). "Cholinergic agonists inhibit HMGB1 release and improve survival in experimental sepsis." Nat Med 10(11): 1216-1221.

Wang, L., R. A. Gordon, et al. (2010). "Indirect inhibition of Toll-like receptor and type I interferon responses by ITAM-coupled receptors and integrins." Immunity 32(4): 518-530.

Weinblatt, M. E., J. S. Coblyn, et al. (1985). "Efficacy of low-dose methotrexate in rheumatoid arthritis." N Engl J Med 312(13): 818-822.

Wu, C. Y., P. L. Chi, et al. (2010). "TLR4-dependent induction of vascular adhesion molecule1 in rheumatoid arthritis synovial fibroblasts: Roles of cytosolic phospholipase A(2)alpha/cyclooxygenase-2." J Cell Physiol 223(2): 480-491.

Yuan, Z., J. Chen, et al. (2008). "Construction and characterization of the HMGB1 mutant as a competitive antagonist to HMGB1 induced cytokines release." Biochem Biophys Res Commun 372(4): 703-707. 
Yue, D., W. Brintnell, et al. (2010). "CTLA-4Ig blocks the development and progression of citrullinated fibrinogen-induced arthritis in DR4-transgenic mice." Arthritis Rheum 62(10): 2941-2952.

Zeuner, R. A., K. J. Ishii, et al. (2002). "Reduction of CpG-induced arthritis by suppressive oligodeoxynucleotides." Arthritis Rheum 46(8): 2219-2224. 


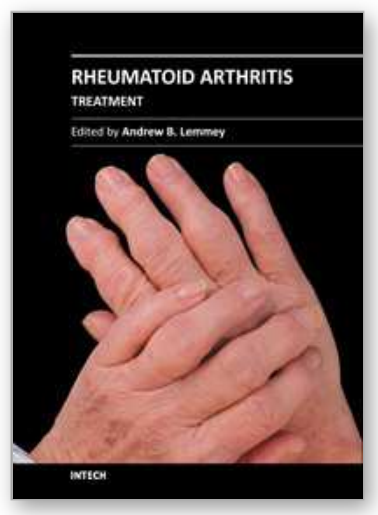

\author{
Rheumatoid Arthritis - Treatment \\ Edited by Dr. Andrew Lemmey
}

ISBN 978-953-307-850-2

Hard cover, 366 pages

Publisher InTech

Published online 18, January, 2012

Published in print edition January, 2012

The purpose of this book is to provide up-to-date, interesting, and thought-provoking perspectives on various aspects of research into current and potential treatments for rheumatoid arthritis (RA). This book features 17 chapters, with contributions from numerous countries (e.g. UK, USA, Canada, Japan, Sweden, Turkey, Bosnia and Herzegovina, Slovakia), including chapters from internationally recognized leaders in rheumatology research. It is anticipated that Rheumatoid Arthritis - Treatment will provide both a useful reference and source of potential areas of investigation for research scientists working in the field of RA and other inflammatory arthropathies.

\title{
How to reference
}

In order to correctly reference this scholarly work, feel free to copy and paste the following:

Theresa H. Page and Kim S. Midwood (2012). Targeting DAMP Activation of Toll-Like Receptors: Novel Pathways to Treat Rheumatoid Arthritis?, Rheumatoid Arthritis - Treatment, Dr. Andrew Lemmey (Ed.), ISBN: 978-953-307-850-2, InTech, Available from: http://www.intechopen.com/books/rheumatoid-arthritistreatment/targeting-damp-activation-of-toll-like-receptors-novel-pathways-to-treat-rheumatoid-arthritis-

\section{INTECH}

open science | open minds

\section{InTech Europe}

University Campus STeP Ri Slavka Krautzeka 83/A 51000 Rijeka, Croatia Phone: +385 (51) 770447 Fax: +385 (51) 686166 www.intechopen.com

\section{InTech China}

Unit 405, Office Block, Hotel Equatorial Shanghai No.65, Yan An Road (West), Shanghai, 200040, China 中国上海市延安西路65号上海国际贵都大饭店办公楼405单元 Phone: +86-21-62489820

Fax: $+86-21-62489821$ 
(C) 2012 The Author(s). Licensee IntechOpen. This is an open access article distributed under the terms of the Creative Commons Attribution 3.0 License, which permits unrestricted use, distribution, and reproduction in any medium, provided the original work is properly cited. 